\title{
LICENSED SHARED ACCESS (LSA) - REGULATORY BACKGROUND AND VIEW OF ADMINISTRATIONS
}

\author{
- INVITED PAPER -
}

\author{
Karsten Buckwitz, Frequency Utilisation Concepts and International Affairs, Federal Network Agency Germany; \\ Jan Engelberg, Finnish Communications Regulatory Authority (FICORA), Finland; \\ Gernot Rausch, Federal Ministry of Transport, Innovation and Technologie, Austria
}

\begin{abstract}
This paper reflects the view of Conférence Européenne des Postes et des Télécommunications (CEPT) Administrations on status and current work on Licensed Shared Access (LSA), related to European Communication Committee (ECC) Decisions and Reports as well as to the current regulatory framework on licensing and sharing.
\end{abstract}

It explains similarities and differences between the grandfathering approach Authorized Shared Access (ASA) and LSA. The latter provides the communication basis for an enhanced future solution for more flexible sharing and is unanimously agreed within the CEPT and the Radio Spectrum Policy Group (RSPG), the high-level advisory group of European Union (EU) Member States that assists the European Commission (EC) in the development of radio spectrum policy.

Reasoned by the duplicities of the approaches the paper aims to compare among the qualities and justifications of both sharing approaches, LSA and ASA. Especially the comprehensive approach provided by the framework of LSA - as amended by CEPT and EC - is highlighted, noting the relevant circumstances of both entities.

Additional focus has been placed on the draft ECC Decision on "Harmonised technical and regulatory conditions for the use of the band 2.3 - 2.4 GHz for MFCN" [1] and its background, especially on its requested implementation via the LSA concept.

Keywords-componen: LSA, ASA, regulatory framework, frequency management, CEPT, EC, RSPG, ECC, $2.3-2.4 \mathrm{GHz}$ band

\section{INTRODUCTION}

Enhancement of spectrum efficiency has become a key issue during the last years, coming along with the raised demands of users, and the related requirements to the services regarding constantly grown traffic. Based on reports by the administrations and interregional organizations the inevitable scarcity of spectrum has been recognized in common shared bands; used by systems and applications for data exchange and communications. Therefore new approaches of sharing have been considered not only by industry and research, but also by Administrations. This has been recognized as a long-term task for further elaboration and development of adequate sharing schemes for Europe.
One of these approaches was the Authorized Shared Access (ASA) concept; created as a tool to assess bands allocated to mobile service (MS) by means of the Radio Regulations but identified and used for different purposes by national decisions of the administrations (and/or regional organizations). The agreement between incumbent and new entrant (merely International Mobile Telecommunications (IMT) in identified bands, for Europe e.g. in $2.3-2.4 \mathrm{GHz}$ bands) was depicted as based on monetary compensation for the duration of use. The agreement (including its bands, duration, and parameters) was, in its first version [2] intended to be established on bilateral basis between incumbent and ASA user only, without any means of control by the national regulatory authority (NRA). Due to the nature of this agreement the ASA user was neither protected, nor able to claim protection with regards to national regulation. Just raising a possible authorization [2][3] by the NRA would not serve towards the wanted protection and Quality of Service (QoS).

For several reasons, including the licensing/sharing issues, the ASA concept of 2011 was taken into account as the basic idea to be enhanced to fit into the regulatory framework of Conférence Européenne des Postes et des Télécommunications (CEPT). The further work on the concept led to the smarter and comprehensive approach of Licensed Shared Access (LSA), which has been identified by the European Commission (EC) and CEPT as the common basis for voluntary sharing within existing licenses in general for Europe, and especially for the implementation of Mobile/Fixed Communication Networks (MFCN) in the $2.3-2.4 \mathrm{GHz}$ bands (see section IV). At the same time industry and research were simultaneously developing the ASA concept as well.

Even though the approaches have been clearly separated by its definitions and related deliverables of the Electronic Communication Committee (ECC) of CEPT and the Radio Spectrum Policy Group (RSPG) of EC, there was a clear confusion in the use of the terms, especially in the past. Therefore, this paper clarifies that any potential licensed shared access in Europe will be based on the LSA approach developed by CEPT's European Communication Committee (ECC) and the Radio Spectrum Policy Group (RSPG) only.

The remaining paper is organized as follows: Section II introduces the European regulatory and section III the key players in the field. The following Section IV is introducing the ECC Decision on the use of the $2.3-2.4 \mathrm{GHz}$ bands. In Section 
$\mathrm{V}$, the existing licensing procedures are discussed in general. Section VI, introduces the LSA concept as complementary tool for the existing schemes. The comparison between LSA and ASA is conducted in Section VII. Finally, conclusions are drawn in Section VIII, together with the recommendation on the future terminology.

\section{REGULATORY FRAMEWORK}

ITU-R Region $1^{1}$ hosts aside CEPT also other interregional organizations (namely the Regional Commonwealth in the field of Communications (RCC), the Arab Spectrum Management Group (ASMG), and the African Telecommunication Union (ATU); directly neighboring the CEPT). This is by itself already a unique situation. But additionally 28 of the 48 CEPT are member states of the European Union or affiliated with it. All the regional and interregional organizations might have different regulatory frameworks and related national implementations, which have to be taken into account and respected as well. CEPT faces very special circumstances of regional and interregional cooperation and therefore needs to focus also on coordination procedures, which are a major issue for densely populated areas, more or less throughout whole Europe.

CEPT, EC and the European Telecommunications Standards Institute (ETSI) are cooperating, based on a Memorandum of Understanding (MoU), on aspects related to the regulatory frameworks for radio equipment and spectrum both at the EU level and at the wider intergovernmental level across Europe [6].

\section{THE PLAYERS}

\section{A. EC, RSPG and RSC}

The EC is the executive body of the European Union (EU), representing and maintaining the interests of the 28 member states. In this scope it proposes matters of legislation to Parliament and Council of the EU, and manages and implements relevant policies for the EU [6]. In contradiction to the voluntary implementation of ECC Decision for CEPT members, EU legislation (in form of EC Directives and Decisions) is binding for EU member states.

The RSPG is the high-level advisory group of the EU member states to the EC (and its related directorates ${ }^{2}$ ) providing views on inquiries and questions of the EC.

In its scope to propose matters of legislation, the EC sought the advice of the RSPG regarding a potential licensed shared access model, which has been provided by the RSPG Opinion on LSA [4], a succeeding action to the Report on collective and shared use [7] deliberations of the former years.

The decision-making process on EU level is set by the EC Radio Spectrum Decision [8]. According to that, before establishing an EU harmonization measure, the EC mandates

\footnotetext{
1 ITU-R is divided into three different regions: Region 1 - Europe, Arabic Countries, Africa; Region 2 - The Americas; Region 3 - East Asia Pacific including Australia and New Zealand

2 The European Commission consists of several directorates, of interest for the radio communications are: DG MOVE - Mobility and Transport; DG ENTR - Enterprise and Industry; DG CONNECT - Communications Networks, Content and Technology
}

CEPT (ECC) via the Radio Spectrum Committee (RSC) to carry out the related technical studies. The cooperation between EC and ECC [6] foresees the provision of technical studies towards EC Decisions to be delivered by the ECC as CEPT Reports, in response to the dedicated EC Mandates.

In spring 2014, the EC presented, within this framework, an EC Mandate on the use of the $2.3-2.4 \mathrm{GHz}$ bands by MFCN [9] to the RSC.

\section{B. ETSI}

A main player in European standardization is the European Telecommunications Standards Institute (ETSI), which is one of the European Standard developing organizations (SDOs) recognized by the EC. ETSI is considered as an independent and non-profit oriented entity with more than 700 members, including NRAs, industry and other relevant organizations. ETSI establishes and maintains technical standards and system reference documents (SRDocs) to provide technical and legal background to the systems under standardization.

ETSI has been tasked by EC Mandate M/512 to, among others to "enable the deployment and operation of cognitive radio systems (CRS) ... under Licensed Shared Access regime". The related work led to the SRDoc TR 103113 [12] and the technical specification TS 103154 [13]. Both deliverables provide information on possible standardization for the frequency band $2.3-2.4$. GHz and are based solely on LSA as introduced and described by CEPT and RSPG.

\section{C. $E C C$}

The CEPT is one of the interregional organizations of ITUR Region 1 consisting of 48 European countries [10], with its technical committee, ECC, is in charge of developing common communication policies and regulatory frameworks for Europe. The results of these developments, in general ECC Decisions and Recommendations approved by consensus, are subject to voluntary implementation by the Member States.

The $27^{\text {th }}$ meeting of ECC working group on frequency management (WG FM) decided, after considering a related Report on ASA (2011) [11] and further requests from European Administrations, to establish two project teams (FM52 and FM53) on the subject; one to deal with the LSA approach in general and the second to develop an ECC Decision, aiming for harmonized implementation measures for MFCN in $2.3-2.4$ $\mathrm{GHz}$ including regulatory provisions based on LSA ensuring the long term incumbent use of the band in the territory of the administrations that wish maintain such use. The work led to ECC Report 205 [5] and ECC Decision on "Harmonised technical and regulatory conditions for the use of the band 2300 - $2400 \mathrm{MHz}$ for MFCN" [1] (see Section IV). Both ECC deliverables are considered as precedence and common basis for future licensed sharing throughout Europe.

\section{ECC DECISION ON THE 2.3 - 2.4 GHz BAND}

The work took into account the requirements and demands as brought forward by the mobile industry on the one hand and the necessary protection of incumbent services on the other. The part on LSA was influenced by the work of FM53 in the general definition of the LSA approach, as presented in ECC Report 205 [5] and based on the related definitions and 
elaborations of the RSPG Opinion on LSA [4]. The ECC Decision, aside defining parameters of the use of the band 2.3 $2.4 \mathrm{GHz}$ for MFCN, including least restrictive technical conditions (LRTC) is describing LSA as a mandatory approach to protect the incumbent's use of the bands for those administrations wishing to do so. In those cases the mobile stakeholders will only get access to the resource, if appropriate spectrum can be made available by the incumbents.

With that emphasize on the implementation of the LSA under mandatory protection of the incumbent users, this new ECC Decision differs notably from other ECC Decisions to harmonize spectrum for the use by MFCN.

\section{LICENSING In GENERAL TERMS}

Acknowledgement of national licensing issues and possible sharing approaches is considered as significant connotation of understanding the chosen regulatory approach by CEPT. Therefore this section aims for appropriate explanation and background.

\section{A. NATIONAL OBLIGATIONS and SHARING APPROACHES}

The Constitution of the International Telecommunication Union (ITU) [14] considers the regulation of the spectrum as "the sovereign right of each State". Therefore frequency management and regulation on national and other levels shall only be maintained by the national regulatory authority (NRA). One of the obligations of the NRA in the sector of frequency management is the proper licensing in terms of equitable (transparent and non-discriminatory) access, minimization and mitigation of interference to all licensees and appropriate channeling, in order to foster efficient use of the scarce resource in respect and adherence of the national and interregional regulatory frameworks and policies. This also covers the coordination with other countries in the relevant region, especially with direct neighbors.

Spectrum is usually individually licensed, mainly categorized in applications, duration and dedicated purpose. Other possible regulatory regimes are the license exemption (equals general licensing) and 'light licensing', which are considered more flexible, but not taken into account in every European country. In general, the concept of general licensing is considered appropriate and successfully introduced in a number of bands worldwide. Disadvantage of such approach is that all the users are considered on equal level, no QoS and probability of access can be guaranteed, due to the nature of the bands and unknown number of users. In Europe, these so called Collective Use of Spectrum (CUS) bands are generally used by a very high number of Short Range Devices (SRDs) in different classes, developed and manufactured to manage the situations in these bands, especially the interferences. Even though a successful heavy trend over the latest years, the ambiguity of the industry and their call for minimum of legal certainty as the basis of spectrum use with regards to their efforts in development and investments remains.

Therefore, from the Administration's point of view only the individual licensing regime can fulfil all the obligations of proper frequency management on the one hand and the requirements of manufacturers and licensees on the other. An individual license will cover the frequency, channels or bands, its conditions of usage (emission limits i.e. power, out-ofband), duration and the constraints with regards to in-band and/or adjacent band compatibility. In terms of protection and provision of legal certainty to the licensees, the individual licensing scheme is preferred by the stakeholders. An individual license will also, by its definition, provide a certain QoS since the number of licensees using the resource is known and their interrelation will have been assessed by the Administration, in cooperation with the licensee(s).

\section{LSA IMPLEMENTATION}

The ASA concept - introduced by industry [2] as a possible enabler for the enhancement of spectrum use efficiency in the bands allocated to land mobile services - was taken into account by CEPT and by RSPG. After thorough assessment both entities concluded that for further consideration of the concept a slightly different approach and more open scope was needed. As widely supported by CEPT, the RSPG activity on LSA enlarged the scope of ASA to the current definitions of LSA [4][5], including the request on reliable QoS and with the involvement of the NRA.

The definition and meaning of LSA provided by RSPG [4] and ECC [5] can be summarized as follows: A regulatory approach to allow any incumbent to share its licensed spectrum with prospective users in accordance with a sharing framework, predefined by the NRA. The possible sharing opportunities are to be discussed between the incumbent and the prospective user, but the result of the related dialogue is subject to approval by the NRA, which will decide on the authorization issuing individual license(s) to the new additional user(s in limited count), containing the relevant sharing arrangement(s).

With the introduction of LSA in accordance to the above, CEPT offers an opportunity for licensed sharing in addition to the existing CUS approach for Europe. LSA describes the sharing among few parties, with guaranteed QoS and a dedicated license, where the partners are involved in a related LSA agreement and are able to rely on adequate legal certainty for developments and investments. It covers therefore both, the general request for flexibility in the fields of sharing as brought forward by industry and research and the accomplishment of the obligations of the Administration, taking care of national (and international) legislation.

\section{COMPARISON BETWEEN ASA \& LSA}

Due to the two cords of evolution of the approaches, the Administrations are more and more requested to take note also of the developed ASA approach, see [3]. The comparison of the approaches LSA [4][5] and ASA [3] in Figure 1 reveals three apparent differences between them:

- the requested level of authorization; and

- the bands where the approach shall be implemented

Also under question is that ASA is still remaining on an open authorization by the NRA, without additional clarification and explanation. Noting the several tools of authorization for the NRAs available, this may lead to ambiguity in the use of the ASA approach by the NRAs. 
Additionally ASA is still targeting the bands allocated to the MS only, to be additionally used by mobile network operators (MNOs). LSA has been developed to cover as many as possible appropriate bands and possible users. The subsequent curtailing of the LSA scheme to a single service band or single group of prospective users will not considered further by the entities (EC and CEPT).

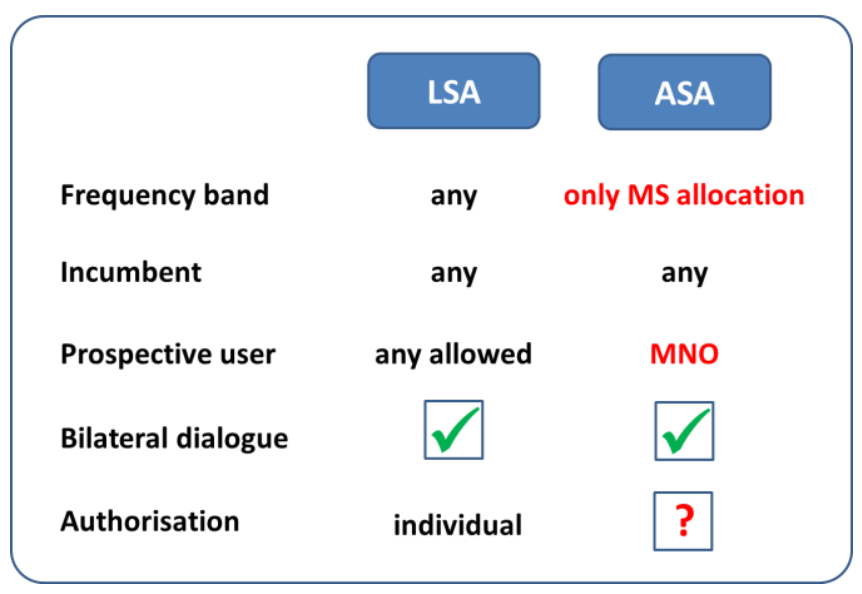

Figure 1 - Comparison between LSA and ASA

\section{CONCLUSION}

The responsible bodies in Europe (EC, CEPT, and ETSI) are only using the term and definitions of LSA in their deliberations on a licensed sharing scheme for Europe, but due to simultaneous developments in the fields of industry and research, the term ASA is also still being used and referenced in a similar way.

The comparison of the two approaches ASA and LSA revealed that both are closely developed and very similar in their ideas. Nevertheless there are remaining differences on the type of authorization and the aimed bands. Noting that the NRA is the only responsible entity to decide on the appropriate authorization scheme, which has been set by European law, they will rely on their most common scheme of authorization.
With regards to the second identified difference, the intended bands for implementation, ASA might be kept as the label of a subset (describing the implementation of MNO in MS bands), while the LSA approach as such covers all possible bands, not limiting the approach to any service specific bands. A dedication of the generalized sharing approach LSA to a single service band or single users group will not be taken into account by the entities (EC and CEPT) noting the requested flexibility.

Therefore this paper closes with the request to industry and research to note and meet the already existing precedence of LSA in order to keep LSA solely in future. The request is reasoned by the need to avoid misunderstanding in discussion and handling of this scheme on licensed sharing for Europe.

\section{REFERENCES}

[1] "Harmonised technical and regulatory conditions for the use of the band 2.3 - $2.4 \mathrm{GHz}$ for MFCN", Draft ECC Decision (14)BB, April 2014.

[2] "ASA - An evolutionary spectrum authorisation scheme for sustainable economic growth and consumer benefit" ECC(11)INFO01, Presentation by ingenious network (Kip Meek). 2011.

[3] "Optimising Spectrum Utilisation towards 2020". NSN. March 2014.

[4] RSPG Opinion on Licensed Shared Access. RSPG13-538, Radio Spectrum Policy Group, Nov 2013.

[5] Licensed Shared Access (LSA), ECC Report 205, Feb 2014.

[6] "Introduction to the European regulatory environment for radio equipment and spectrum" Interrelation of the ECC. 2011.

[7] Report on Collective Use of Spectrum (CUS) and other spectrum sharing approaches. RSPG11-392, Radio Spectrum Policy Group, Nov 2011.

[8] Decision 243-/2012/EU. EU CIRCABC. Mar 2012.

[9] EC Mandate on MFCN for 2.3 - 2.4 GHz. RSC. Mar 2014.

[10] "All about our Organisation" Leaflet of the ECC. 2011.

[11] Report on ASA concept, ECC WGFM, FM(12)084 Annex 47. 2012.

[12] Mobile Broadband services in the $2300-2400 \mathrm{MHz}$ frequency band under Licensed Shared Access regime. ETSI TR 103.113 v 1.1.1, July 2013.

[13] System requirements for operation of Mobile Broadband Systems in the $2300 \mathrm{MHz}-2400 \mathrm{MHz}$ band under Licensed Shared Access (LSA) regime. Draft ETSI TS 103 154, 2014.

[14] Constitution and Convention, Preamble. ITU. 2010 